\title{
Weathering prediction model for stored liquefied natural gas (LNG)
}

\author{
Calogero Migliore ${ }^{1,2}$, Cristina Tubilleja ${ }^{2}$, Velisa Vesovic ${ }^{1, *}$
}

\author{
${ }^{1}$ Department of Earth Science and Engineering, Imperial College London, \\ London SW7 2AZ, United Kingdom \\ ${ }^{2}$ Repsol, S.A., Centro de Tecnología Repsol, Carretera Extremadura A-5, km. 18, \\ Móstoles, 28935, Madrid, Spain
}

Key words: LNG, Modelling, BOG, Weathering, Vaporization

*corresponding author: Tel: +44 207594 7352; E-mail: v.vesovic@imperial.ac.uk 


\begin{abstract}
A model is proposed to predict the weathering of LNG stored in containment tanks, typically used in regasification terminals, due to the effects of heat ingress and Boil-off-Gas (BOG) release. The model integrates a rigorous thermodynamic model of LNG vapour-liquid equilibrium and a realistic heat transfer model. It provides a number of advances on previously developed models, in so far as: (i) heat ingress is calculated based on the outside temperature and LNG composition, that allows for daily or seasonal variation; (ii) Boil-off-Ratio is not an input parameter, but is calculated as part of the simulations and (iii) the LNG density is estimated using an accurate experimentally based correlation.

The model was validated using real industry data and the agreement obtained in predicting the overall composition of weathered LNG, its density and the amount vaporized was within current industry requirements. The model was run in the predictive mode to explore the sensitivity of BOG to different scenarios. In the initial stages of weathering the nitrogen content of LNG will have a marked effect on BOG generation. Even the presence of $0.5 \%$ of nitrogen will lead to nearly a $7 \%$ decrease in BOG, making the initial BOG unmarketable. The high sensitivity is a result of preferential evaporation of nitrogen and increase in the direct differential molar latent heat. In the final stages of weathering the heavier hydrocarbons govern the dynamics of BOG which becomes a strong function of the initial composition and the level of LNG remaining in the storage tank.

The change in ambient temperature of $1{ }^{\circ} \mathrm{C}$ will lead to a change in BOG of $0.2 \%$, irrespective of the size of the tank and initial LNG composition.
\end{abstract}




\section{Introduction}

As a society, we face a number of challenges due to the high demand for energy. It is recognized that these have to be balanced against the need to mitigate ever increasing carbon dioxide emissions, without compromising the longer term energy security. In this context natural gas is seen by many as an optimal vehicle to ensure an orderly transition from the fossil-fuel driven economy to one driven by renewable energy [1]. Currently the share of natural gas in the global energy mix is around 20\%, with forecasts indicating that the demand for natural gas by 2035 is expected to be $50 \%$ higher than today [1]. The increase in demand translates to increasing trade in natural gas, with some forecasts indicating doubling of the current trade.

Natural gas is either transported through pipelines, as gas at high pressure, or it is liquefied and transported as liquefied natural gas (LNG). The choice depends primarily on the distance, but also on the location of the gas field and issues concerning the security of supply. The fact that natural gas can be liquefied in commercial quantities has made the development of the LNG chain possible, thus increasing the availability and versatility of natural gas. The LNG is transported by special marine carriers from the production facilities to regasification terminals, where it is stored in highly insulated storage tanks at pressures slightly above atmospheric and temperatures corresponding to its bubble point. Due to the heat in-leak into the storage tank some of the LNG will vaporize, resulting in an increase in overall pressure. In order to avoid overpressurization of the tank, the boil-off gas (BOG) is continuously removed by BOG compressors at the rate at which the LNG vaporizes, thus maintaining the constant pressure in the tank. As LNG vaporizes, the more volatile components (methane and nitrogen) will vaporize preferentially and the remaining LNG will get richer in the heavier components (ethane, propane, etc.). Over time the composition of LNG will change and that will influence not only its thermodynamic properties, in particular the boiling temperature and latent heat, but also its heating value. The process of preferential vaporization is known in the LNG industry as weathering and can be summarized as progressive alteration of thermophysical properties of stored LNG through vaporization, due to the heat ingress from the surroundings.

Weathering prediction of stored LNG is of particular significance to the LNG industry, especially in LNG shipping and in the operation of regasification facilities. In LNG shipping, it helps to anticipate the allocation of LNG cargoes and to set up in advance the operation of the receiving terminal. In the regasification terminal an accurate estimation of the weathering effect on the received LNG allows to plan operating procedures in advance in order to ensure the suitability of the delivered natural gas in terms of its properties and heating value. In regasification facilities, weathering has 
been traditionally a minor problem in base load $^{1}$ terminals, compared to peak-shaving ${ }^{2}$ installations; however, today's combined effect of sudden fluctuations in the regional gas price and seasonality is producing an increase in the storage time, hence the accurate prediction of weathering becomes important in evaluating the compatibility of the stored LNG with the supplied gas system and final users. Furthermore, if LNG has undergone a substantial weathering in a storage tank its boiling temperature and density will increase as a consequence of it being richer in heavier components. If a new batch of LNG is introduced, that will by necessity be lighter and cooler, a number of undesirable events, involving stratification, sudden vapour release and a possible roll-over, can take place that can endanger normal operations.

For stored LNG, the amount and quality of produced BOG depends on the initial composition, the insulation of the LNG tank and primarily on the time elapsed since the tank was filled. In LNG shipping, the liquid stock in a LNG carrier remains almost constant during the trip from the production facility to the receiving terminal. The longest trips are of the order of 20 days during which $2-3 \%$ of the total volume of the transported LNG evaporates. The usual approach, to predict LNG weathering during marine transport, is to assume the constant boil-off rate (BOR), where the BOR is defined as the ratio of volume, in liquid terms, of LNG that has evaporated in one day, relative to the initial LNG volume in the tank. The BOR figure used in industry for LNG carriers depends on carrier size. For smaller and older ships a BOR of $0.15 \%$ tends to be used [2], while for the latest LNG tankers with an average capacity of $170,000 \mathrm{~m}^{3}$ the BOR is nearer to $0.1 \%$. To predict the weathering in above ground LNG storage tanks, typically used in regasification terminals, the situation is somewhat different. A constant BOR tends to be assumed based on the value adopted during the design stage when a maximum BOR value is specified, usually around $0.05 \%$ [3], and the tank insulation is designed accordingly.

BOR was initially studied in the early stages of the LNG industry by a number of workers [4-5] who focused on the influence of insulation and radiative cooling of the vapour exposed section of the wall on BOR, assuming steady-state and without taking compositional variation of LNG into account. In 1999 the Institute of Gas Technology (IGT) [6] conducted an experimental test program to measure LNG weathering in on-board storage tanks. The experimental set up measured the evolution of composition, mass and temperature of stored LNG in a pressurized container under controlled constant heat inflow, utilizing different LNG compositions. Recently Dimopoulos and Frangopolous [7] and Miana and co-workers [8] independently studied LNG weathering during

\footnotetext{
${ }^{1}$ Base load is the rate of production below which demand is not expected to fall during a given period

${ }^{2}$ A peak-shaving installation is a facility used to store surplus natural gas to meet demand requirements during peak consumption periods (typically in winter)
} 
marine transport. The former developed a rigorous model, based on treating LNG as an ideal mixture and constant heat ingress into the stored LNG, while Miana et al. [8] developed two models (physical model and i-model) with the aim of predicting the LNG composition and properties at the receiving terminal.

A number of researchers [9-11] have recently investigated boil-off from LNG storage tanks. Of special interest to this study is the work of Pellegrini et al. [11] who have developed a weathering model for LNG stored in above-ground tanks based on mass and energy balance, but without the assumption of constant BOR. The model assumes thermodynamic equilibrium for the stored LNG, ideal mixture for enthalpy of vapour and liquid and uses the SRK equation of state (EOS) for phase equlibria and density calculation, with the Penéloux correction for liquid density. The assumption of constant heat ingress limits the model in terms of its applicability to conditions where both the outside temperature and the LNG boiling temperature do not show large temporal variation.

In this work we present a new model aiming to predict the vaporization rate and the compositional variation of LNG stored in a full containment above-ground tank, due to the effects of heat ingress and BOG vapour release. The model is developed by integrating: (i) a rigorous LNG vapor-liquid equilibrium (VLE) model and (ii) a realistic heat transfer model, into an integrated model to predict the compositional variation of the stored LNG. The model builds on the previously published work, but removes a number of constraints that exist in the reported models [6-13], namely: (i) heat ingress is calculated based on the outside temperature and LNG composition, that allows for daily or seasonal variation; (ii) BOR is not an input parameter, but is calculated as part of the simulations and (iii) the LNG density is estimated using an accurate experimentally based correlation, thus replacing the need for an estimate based on EOS that for two parameter cubic EOS requires an empirical correction. 


\section{Model development}

Here we consider the development of the model for the LNG weathering in a typical aboveground storage tank, schematically shown in Figure 1, used in industry to store received LNG.

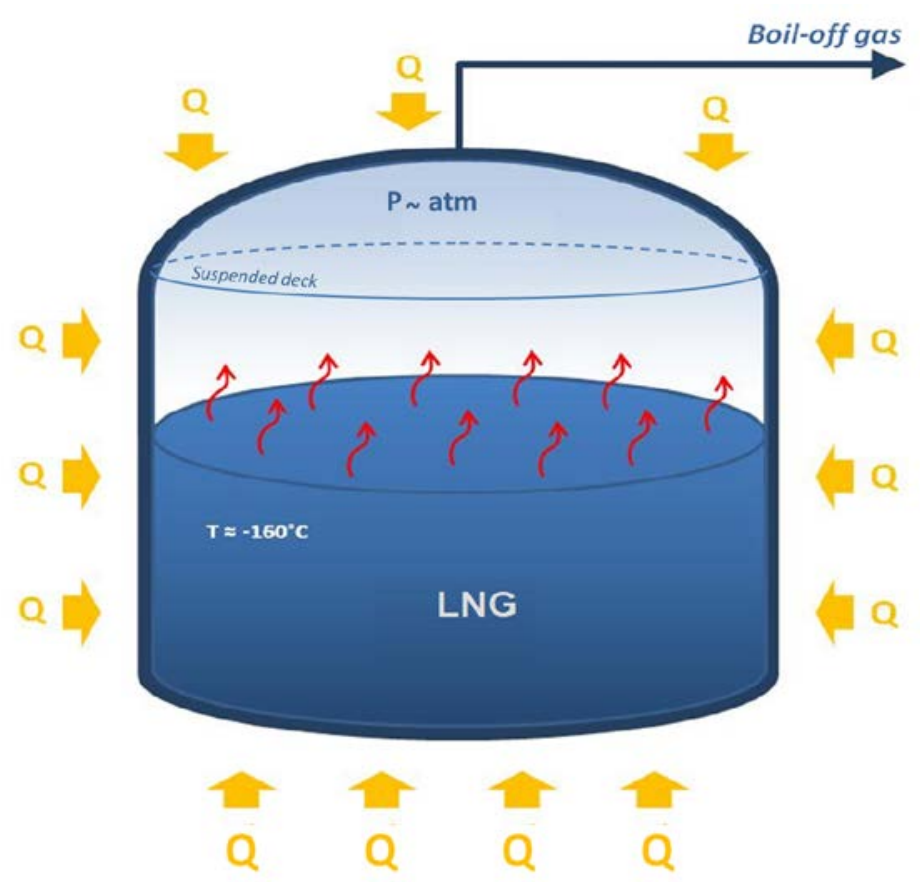

Figure 1 Schematic of LNG storage tank

As the heat ingresses into the stored LNG it causes the preferential vaporization of the lighter components, with the produced vapour (BOG) being removed to control the tank pressure. The energy balance over the storage tank links the amount of heat entering the tank per unit time, $Q$, to the rate of vapour removal, $\dot{B}$ and can be simply expressed as,

$$
Q_{i \mathrm{n}}=\frac{d H_{\mathrm{V}}}{d t}+\frac{d H_{\mathrm{L}}}{d t}+\dot{B} h_{\mathrm{V}}
$$

where $H$ and $h$ are the enthalpy and molar enthalpy, respectively, while subscripts $V$ and $L$ indicate vapour and liquid, respectively. The rate of vapour removal can be obtained from the mass balance,

$$
-\dot{B} \equiv-\frac{d B}{d t}=\frac{d\left(\rho_{\mathrm{L}} V_{\mathrm{L}}\right)}{d t}+\frac{d\left(\rho_{\mathrm{V}} V_{\mathrm{V}}\right)}{d t}
$$


where $\rho$ is the molar density and $V$ is the volume of the storage tank occupied by both the liquid, $V_{\mathrm{L}}$, and vapour, $V_{\mathrm{V}}$. Taking into account that the volume of the tank is constant,

$$
\frac{d V_{\mathrm{L}}}{d t}=-\frac{d V_{\mathrm{V}}}{d t}
$$

one can after some rearrangement express equation (2) as,

$$
\frac{1}{\rho_{\mathrm{V}}} \frac{d B}{d t}=\frac{d V_{\mathrm{V}}}{d t}\left(\frac{\rho_{\mathrm{L}}}{\rho_{\mathrm{V}}}-1\right)-\frac{V_{\mathrm{V}}}{\rho_{\mathrm{V}}} \frac{d \rho_{\mathrm{V}}}{d t}-\frac{V_{\mathrm{L}}}{\rho_{\mathrm{L}}} \frac{d \rho_{\mathrm{L}}}{d t}
$$

where $d V_{\mathrm{V}} / d t$ is the rate of evaporation of LNG. If we substitute Eq. (4) into Eq. (1) we end up with the equation that governs how the ingress of heat changes the thermodynamic state of the stored LNG. As the right-hand side of the resulting equation contains only thermodynamic quantities and their evolution with time, it can be in principle obtained from an appropriate thermodynamic model.

The heat ingress into the storage tank comprises heat transfer through the lateral walls, roof and bottom slab. In industrial storage tanks, the tank bottom slab is maintained at constant temperature using an electrical heating element and temperature sensors, to prevent ground freezing. Thus, in the current model the heat transfer through the bottom of the tank was assumed to be constant and independent of the temperature of the surrounding. In most industrial storage tanks the external roof section is separated from the tank by the insulated, suspended deck. The space between the roof and the suspended deck is filled with BOG. Thus, the heat ingress through the tank roof was also considered to be constant and independent of outside temperature, in the development of this weathering model.

The heat ingress through the tank walls depends on the temperature of the surrounding air and the liquid level in the tank. As the heat transfer from the surrounding air to the inside of the tank is by combination of conduction and convection, one can write the expression for $Q$ as,

$$
Q=U \cdot A \cdot \Delta T=\left(U_{\mathrm{wet}} A_{\mathrm{wet}}+U_{\mathrm{dry}} A_{\mathrm{dry}}\right) \cdot\left(T_{\mathrm{air}}-T\right)
$$

where $U$ is the overall heat transfer coefficient, $A$ is the contact area and subscripts wet and dry refer to the section of the tank filled with liquid and vapour, respectively. Here we assume that the vapour and the liquid inside the tank are at equilibrium at temperature $T$, while the air outside is at temperature $T_{\text {air. }}$. 
Equations (1), (4) \& (5) constitute the working model. Before they can be used to calculate the LNG weathering they have to be supplemented by the thermodynamic model that will provide how the enthalpy and density (see Eqs. (1) and (4) ) of the vapour and liquid change with time.

\subsection{Thermodynamic model}

As previously discussed LNG consist primarily of methane with some ethane and small amounts of nitrogen, propane and butanes. On heating, the presence of other components, even in small quantities, results in preferential vaporization of the light components and increase of heavier components in the remaining LNG. Not only do the thermodynamic properties of LNG change with time, but so does its boiling temperature. In order to properly account for these phenomena we need to be able to calculate the composition of the vapour and liquid phase as a function of time. For this purpose we assume that the two phases are in thermodynamic equilibrium and carry out vapour-liquid equilibria (VLE) calculations. In order to develop as realistic model of the LNG weathering as possible, we obtain the equilibrium constants from the ratios of fugacity coefficients, $\phi_{1}$, of two phases, namely,

$$
K_{i}=\frac{y_{i}}{x_{i}}=\frac{\phi_{i}^{L}}{\phi_{i}^{V}}
$$

where $y$ and $x$ are mole fraction of species $i$ in the vapour and liquid phase, respectively. The fugacity coefficients, $\phi_{i}$, are obtained from the Peng-Robinson Equation of State (PR-EOS),

$$
\left(P+\frac{a}{v(v+b)+b(v-b)}\right)(v-b)=R T
$$

where $a$ and $b$ are the effective parameters [14]. The PR-EOS is still an equation of choice for Oil \& Gas industry, because of its simplicity, versatility and to a certain extent reasonable compositional accuracy for the light reservoir fluids like natural gas. We have made use of standard van der Waals (vdW) mixing rules for $a$ and $b[14,15]$, namely,

$$
\begin{gathered}
a=\sum_{i} \sum_{j} x_{i} x_{j} a_{i j} \\
a_{i j}=\left(1-k_{i j}\right) \sqrt{a_{i} a_{j}} \\
b=\sum_{i} x_{i} b_{i}
\end{gathered}
$$


where $a_{i}$ and $b_{i}$ for each species making the mixture are estimated in a traditional way from their critical temperature and pressure $[14,15]$, together with the binary interaction coefficients $k_{i j}[14]$.

The density of the vapour phase is obtained by solving the PR-EOS for a given pressure and temperature. The density of the liquid phase can be obtained in a similar manner, but it is known that PR-EOS, or for that matter any two parameter cubic EOS that uses critical temperature and pressure to calculate the parameters $a$ and $b$, will underestimate the liquid density. In order to correct for this deficiency one uses an empirical approach based on the volume shift concept [14]. Although this is standard practice to estimate the reservoir fluid density in the Oil and Gas industry, in this work we have opted to use the revised Klosek-McKinley method as it was specifically developed for estimating the density of LNG [16]. It is a reliable and accurate method that is frequently used for custody transfer purposes and is the recommended option by the Groupe International des Importateurs de Gaz Naturel Liquéfié - GIIGNL (International Group of Liquefied Natural Gas Importers) and the ISO 6578. It is valid over the compositions and boiling temperatures of interest to LNG industry and has a claimed uncertainty of $\pm 0.1 \%$, providing either the nitrogen or butane content does not exceed $4 \%$. The method is based on an empirical correlation for the molar volume of the LNG mixture,

$$
v=\sum_{i} v_{i} x_{i}-\left[k_{1}+\left(k_{2}-k_{1}\right)\left(\frac{x_{N 2}}{0.0425}\right)\right] x_{C 1}
$$

where $k_{1}$ and $k_{2}$ are temperature dependent correction factors, while $v_{\mathrm{i}}$ is the molar volume of species $i$. Values for all the coefficients and molar volumes are readily available in a tabular form [16]. It is interesting to note that for nitrogen-free LNG assuming ideal mixture behaviour will overpredict the liquid density by at most $2 \%$, within the range of validity of Klosek-McKinley correlation. However, the predictions based on PR-EOS without the volume shift correction would overpredict the density by $12-16 \%$ for LNG compositions of interest to this work.

The molar enthalpies of each phase can be related to PVT properties by means of residual enthalpy,

$$
\frac{h-h^{i d}}{R T}=Z-1+\frac{1}{R T} \int_{\infty}^{v}\left[T\left(\frac{\partial P}{\partial T}\right)_{v}-P\right] d v
$$

where $h^{\text {id }}$ is the ideal gas enthalpy given by, 


$$
h^{i d}=\sum_{i} x_{i} h_{i}^{i d}
$$

Substituting PR- EOS, eq. (7), into the right hand side of Eq. (12) one obtains [17],

$$
\frac{h-h^{i d}}{R T}=Z-1-\frac{1}{2 \sqrt{2} b R T}\left(a-T \frac{d a}{d T}\right) \ln \left(\frac{v+(1+\sqrt{2}) b}{v+(1-\sqrt{2}) b}\right)
$$

Hence one can evaluate the molar enthalpy at a given temperature and density from the knowledge of PR-EOS parameters $a(T), b$ and a value of compression factor $Z(Z=P V / R T)$. The ideal gas enthalpies of each species in Eq (13) were obtained from a REFPROP database [18].

\subsection{Storage Tank}

The walls of the above ground LNG tank are modelled using a realistic description of the tank walls which in general, consist of at least three clearly defined insulating layers. Figure 2 illustrates the schematic of the wall section of a typical above-ground LNG storage tank, illustrating different diameters.

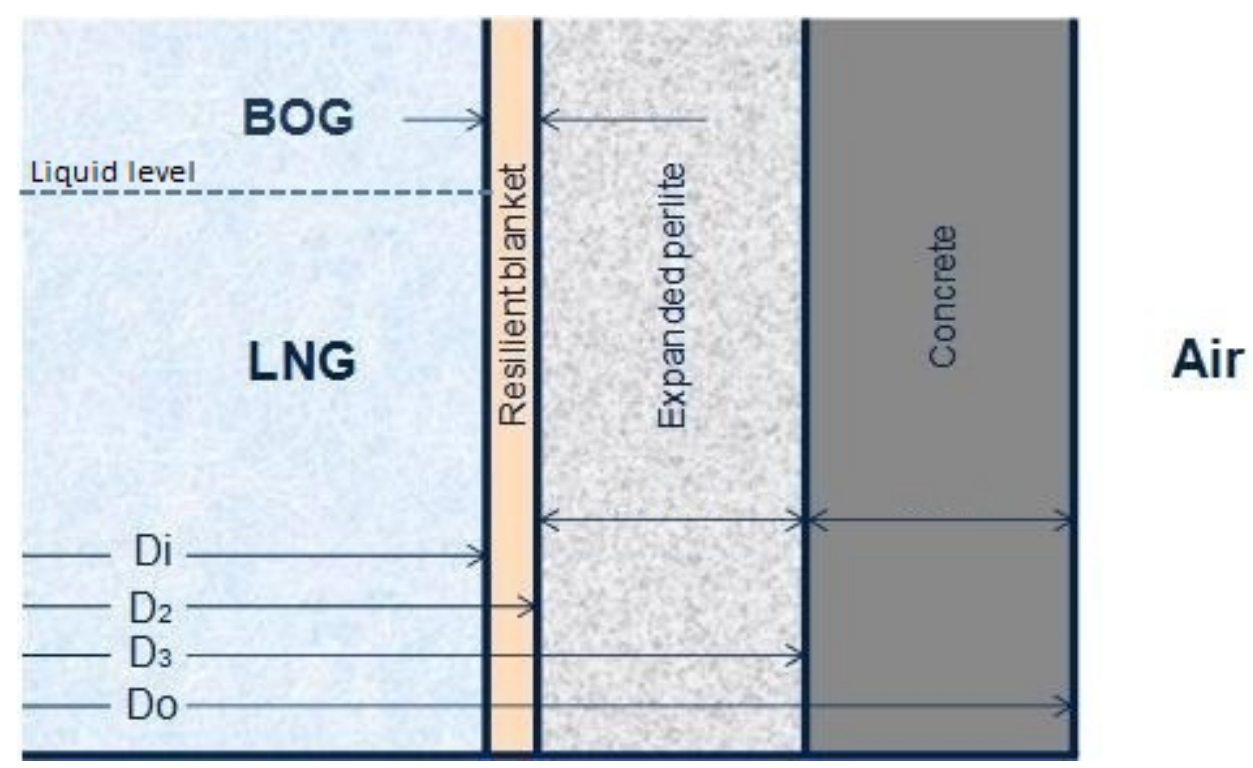

Figure 2 Above-ground LNG storage tank wall section

To calculate the overall heat transfer coefficient, $U_{0}$, we considered heat transfer by convection from the surrounding air to the outside wall, by conduction through the three layered insulated 
wall and by internal convection to the inside of the storage tank. The expression based on the external area is as follows,

$$
\frac{1}{U_{j}}=\frac{1}{h_{\mathrm{o}}}+\frac{A_{\mathrm{o}}}{A_{\mathrm{i}} h_{\mathrm{i} j}}+\sum_{l=1}^{3} \frac{A_{\mathrm{o}}}{A_{\mathrm{m} l}} \frac{e_{l}}{k_{l}}
$$

where $e$ is equivalent insulation thickness, $k$ is thermal conductivity of layer material, $h$ is the convection heat transfer coefficient, and subscripts $i$ and $o$ refer to internal and external, respectively. The subscript $j$ refers to wet or dry part of the inside wall, while subscript $I$ is used to denote different insulating sections of the wall. It is assumed that the metal wall offers only a very small resistance to transfer of heat and its thermal conductivity is neglected. If one works in terms of equivalent diameter defined as,

$$
D_{\text {eq. }}=\frac{D_{\mathrm{o}}-D_{\mathrm{i}}}{\ln \left(D_{\mathrm{o}} / D_{\mathrm{i}}\right)}
$$

rather than in terms of the mean heat transfer area, $A_{m}$, one can rewrite equation (15) as,

$$
\frac{1}{U_{j}}=\frac{1}{h_{\mathrm{o}}}+\frac{D_{\mathrm{o}}}{D_{\mathrm{i}} h_{\mathrm{i} j}}+\sum_{l=1}^{3} \frac{D_{\mathrm{o}}}{D_{\mathrm{eq} . l},} \frac{e_{l}}{k_{l}}
$$

The external and internal convection heat transfer coefficients, $h_{\mathrm{o}}$ and $h_{\mathrm{ij}}$, considered for this study were calculated using standard chemical engineering expressions [19] for natural convection in terms of Grashof and Prandtl numbers. 


\section{Calculation procedure and model testing}

The prediction of LNG weathering based on the model described in the previous section requires solving simultaneously the heat balance, Eqs. (1 and 4), and VLE, Eqs. (6-10). In order to do this we have adopted an iterative procedure. We start by defining the storage tank dimensions, operating pressure, initial inventory, initial LNG composition and ambient temperature. We solve Eqs. (1) and (4) using finite difference method by specifying a time step. For the purposes of this work the time step of half a day was more than sufficient to lead to convergent solution for all the variables of interest. This is broadly in agreement with studies by Dimopoulos and Frangopolous [7] that concluded that 1-day time-step is sufficient for convergence for 25 day marine transportation. In order to solve Eq. (1) and (4), we first evaluate the amount of heat that has entered the storage tank during a given time step by recourse to Eqs. (5, 16-17). We then estimate the new temperature in the tank and iterate around temperature until the right hand side of combined Eqs. ( 1 and 4 ) is equal to heat ingress for that time step. At each temperature the calculation involves first the equilibrium calculation based on Eq. (6) and PR-EOS. A standard procedure [14] based on the solution of Rachford-Rice equation is employed with Newton-Raphson method used to speed up the convergence. The convergence is defined by setting the vapour mole fraction tolerance of $1 \times 10^{-10}$. Once the composition of the vapour phase is determined the density of the vapour phase is calculated using PR-EOS, while the density of the liquid phase is estimated by means of Eq. (11). The enthalpies of both phases are calculated by means of Eq. (13-14). The model has been built in MS Visual Basic 6.0 software platform [20].

The vapour-liquid equilibrium (VLE) module of the developed LNG weathering model was initially validated by comparing the predictions against the results obtained with Aspen-Hysys simulator [21] for vapour composition and equilibrium temperature. The validation was performed for a number of LNG compositions including LNG with high nitrogen content $\left(0.57 \% \mathrm{~N}_{2}\right)$ and heavy LNG $\left(87 \% \mathrm{C}_{1}\right.$ and $\left.13 \% \mathrm{C}_{2+}\right)$. In all the cases the mole fractions of major components $(x>0.01)$ in the vapour phase were in agreement to better than $1 \%$. For minor components deviations up to $2 \%$ were observed.

The second assessment was performed by comparing the latent heat predicted by the developed model against the calculations based on the exact thermodynamic relationships. The latent heat predicted by the model was estimated simply by dividing, at each time step, the vaporization rate by the heat ingress. We limited our investigation to three binary LNG-like mixtures ( mixture 1: 96\% mole $C_{1}$ and $4 \%$ mole $C_{2}$; mixture 2: $89 \%$ mole $C_{1}$ and $11 \%$ mole $C_{2}$ and mixture 3: $96 \%$ mole $\mathrm{C}_{1}$ and $4 \%$ mole $\mathrm{N}_{2} ;$ ) in order to take advantage of relatively simple thermodynamic relationships for the latent heat of binary mixtures. For mixtures that are undergoing isobaric phase change one 
needs to distinguish between the overall and differential latent heat. The former is simply the difference between the molar or specific enthalpy of the vapour and liquid phase at equilibrium and corresponds to the amount of heat necessary to evaporate the whole mixture. The latter corresponds to the amount of heat necessary to evaporate an infinitesimal amount of liquid mixture under isobaric conditions. As the liquid phase gets progressively richer in the heavier component its boiling temperature increases and it is customary to separate the differential latent heat into direct and indirect latent heats $[22,23]$. The direct component can be ascribed to the change in entropy during isobaric evaporation between a mole of liquid $\left(x_{1}, x_{2}\right)$ and a mole of vapour $\left(y_{1}, y_{2}\right)$, while indirect component arises due to change in temperature which accompanies isobaric evaporation. The direct and indirect differential latent heat, for a binary mixture, can be expressed in terms of thermodynamic quantities by the following relationships [22, 23],

$$
\begin{gathered}
L_{\text {direct }}=\frac{n^{l}\left(\frac{\partial x_{1}}{\partial T}\right)_{P, b} T\left[y_{1}\left(s_{1}^{v}-s_{1}^{l}\right)+y_{2}\left(s_{2}^{v}-s_{2}^{l}\right)\right]+n^{v}\left(\frac{\partial y_{1}}{\partial T}\right)_{P, d} T\left[x_{1}\left(s_{1}^{v}-s_{1}^{l}\right)+x_{2}\left(s_{2}^{v}-s_{2}^{l}\right)\right]}{n^{l}\left(\frac{\partial x_{1}}{\partial T}\right)_{P, b}+n^{v}\left(\frac{\partial y_{1}}{\partial T}\right)_{P, d}} \\
L_{\text {indirect }}=\frac{\left(x_{1}-y_{1}\right)\left(n^{l} C_{p}^{l}-n^{v} C_{p}^{v}\right)}{n^{l}\left(\frac{\partial x_{1}}{\partial T}\right)_{P, b}+n^{v}\left(\frac{\partial y_{1}}{\partial T}\right)_{P, d}}
\end{gathered}
$$

where $C_{\mathrm{p}}, s$ and $n$ are molar heat capacity, molar entropy and number of moles, respectively, of each phase. The thermodynamic quantities entering Eqs (18-19) were obtained from Aspen-Hysys process simulator [21] for each assessed mixture. The simulations were run for the period of 52 weeks. During this period only mixture 3 exhibited changes in the total differential latent heat, as the vapour consisted of varying amounts of nitrogen in addition to methane. For all three LNG-like mixtures the differntial latent heat calculated by two methods was in agreement to within $5 \%$. 


\section{Results and discussion}

\subsection{Comparison with measured data and previous studies}

As the final validation test we have compared the prediction of our model with selected data obtained from historical cargo measurements. The same data were used by Miana et al. [8] to assess their models (physical model and i-model), specifically developed for LNG weathering during ship transportation. As measured data were obtained for LNG weathering during the marine transport, a minor change was incorporated in the heat transfer module of our integrated model. We have made use of constant BOR of $0.15 \%$, quoted Miana et al. and routinely used in shipping industry, to adjust the overall heat transfer coefficient $U\left(U=\sim 0.36 \mathrm{~W} / \mathrm{m}^{2} / \mathrm{K}\right)$ in eq (5). Hence this validation tests only the thermodynamic module and mass balance equations that we have implemented in our model.

Table 1 compares the predictions of our model with the measured LNG data for three different journeys that were also utilized by Miana et al. [8] in their study. In order to obtain the results given in Table 1 we have only used the quoted initial compositions of the LNG [8], also given in Table 1, and the duration of the trip as inputs in our model, together with the assumption of constant BOR, described previously. The agreement with measured data is excellent. Journey 1 is of short duration (126.5 hours) and LNG is of high methane content. Our model reproduces the measured compositional data to better than 0.001 of mole fraction, the final volume and temperature to better than $0.02 \%$, while the predicted density is within $0.15 \%$ of the measured value. If we examine Journey 2 which lasted 3 times as long (390 hours) and where the initial content of methane was much lower, the agreement is still very good. Our model reproduces the measured compositional data still to better than 0.001 of mole fraction, the final volume and temperature to better than $0.12 \%$, while the predicted density is within $0.05 \%$ of the measured value. All the measured data on other journeys reported by Miana et al. are reproduced with similar accuracy. The only exception is Journey 3 , illustrated in Table 1 , where our model reproduces the measured compositional data to within 0.002 of mole fraction, the final volume to better than $0.12 \%$, while the predicted density and temperature is within $0.7 \%$ of the measured value. The results are surprising as this is the shortest journey (98 hours), although the methane content is lower and nitrogen content higher than in other reported journeys. However, the cursory analysis of experimental data indicates that some of the measurements might have a larger uncertainty than previously assumed. For instance, based on the quoted volumes and nitrogen content measured at the port of origin and destination, one can estimate that nitrogen evaporation alone led to $96 \mathrm{~m}^{3}$ decrease in the amount of LNG. However, based on quoted total volumes only $70 \mathrm{~m}^{3}$ of LNG has evaporated as BOG. It is also worth noting that the experimental error in measuring the 
composition of trace components (n-C5 \& i-C5) at the two ports is large, which is not surprising as they both constitute less then $0.05 \%$ of the overall mixture. During the weathering process we expect the composition of heavy components in LNG to increase. As can be seen from the measured values, see Table 1, this is not always the case.

Table 1 LNG weathering predictions compared with measured data at the port of arrival [8]

Journey 1

\begin{tabular}{|c|c|c|c|c|c|c|c|c|c|}
\hline \multirow[b]{2}{*}{$\begin{array}{c}\text { Component } \\
\text { mole \% }\end{array}$} & \multicolumn{3}{|c|}{ Measured values } & \multicolumn{2}{|c|}{ Measured values } & \multicolumn{4}{|c|}{ Measured values } \\
\hline & $\begin{array}{l}\text { Port of } \\
\text { origin }\end{array}$ & $\begin{array}{l}\text { Port of } \\
\text { arrival }\end{array}$ & $\begin{array}{c}\text { Predicted } \\
\text { values }\end{array}$ & $\begin{array}{l}\text { Port of } \\
\text { origin }\end{array}$ & $\begin{array}{l}\text { Port of } \\
\text { arrival }\end{array}$ & $\begin{array}{c}\text { Predicted } \\
\text { Values }\end{array}$ & $\begin{array}{c}\text { Port of } \\
\text { origin }\end{array}$ & $\begin{array}{l}\text { Port of } \\
\text { arrival }\end{array}$ & $\begin{array}{c}\text { Predicted } \\
\text { values }\end{array}$ \\
\hline $\mathrm{C}_{1}$ & 97.180 & 97.294 & 97.162 & 90.300 & 90.142 & 90.219 & 87.417 & 87.722 & 87.441 \\
\hline $\mathrm{C}_{2}$ & 2.480 & 2.410 & 2.500 & 6.160 & 6.399 & 6.304 & 8.95 & 9.018 & 8.995 \\
\hline $\mathrm{C}_{3}$ & 0.170 & 0.156 & 0.171 & 2.250 & 2.300 & 2.303 & 2.226 & 2.210 & 2.237 \\
\hline $\mathrm{i}-\mathrm{C}_{4}$ & 0.060 & 0.057 & 0.060 & 0.370 & 0.389 & 0.379 & 0.286 & 0.276 & 0.287 \\
\hline $\mathrm{n}-\mathrm{C}_{4}$ & 0.030 & 0.029 & 0.030 & 0.550 & 0.578 & 0.563 & 0.370 & 0.355 & 0.372 \\
\hline $\mathrm{i}-\mathrm{C}_{5}$ & 0.000 & 0.019 & 0.000 & 0.010 & 0.005 & 0.010 & 0.019 & 0.020 & 0.019 \\
\hline $\mathrm{n}-\mathrm{C}_{5}$ & 0.050 & 0.007 & 0.050 & 0.000 & 0.001 & 0.000 & 0.017 & 0.016 & 0.017 \\
\hline $\mathrm{N}_{2}$ & 0.030 & 0.028 & 0.025 & 0.360 & 0.186 & 0.222 & 0.715 & 0.383 & 0.632 \\
\hline \multicolumn{2}{|c|}{ Trip duration, $\mathrm{h}$} & 126.5 & & & 390 & & & 98.0 & \\
\hline$T_{\text {boiling, }}{ }^{\circ} \mathrm{C}$ & -159.8 & -159.8 & -159.8 & -159.9 & -159.9 & -159.7 & -161.4 & -160.1 & -161.1 \\
\hline$V, \mathrm{~m}^{3}$ & 136,012 & 134,984 & 135,014 & 136,089 & 133,147 & 133,305 & 28,818 & 28,748 & 28,709 \\
\hline$\rho, \mathrm{kg} / \mathrm{m}^{3}$ & 429.596 & 429.052 & 429.694 & 457.035 & 457.710 & 457.495 & 465.735 & 462.959 & 466.111 \\
\hline$W I, M J / m^{3}$ & 54.14 & 54.11 & 54.15 & 55.58 & 55.78 & 55.73 & 55.68 & 55.90 & 55.75 \\
\hline$H H V, M J / \mathrm{m}^{3}$ & 40.92 & 40.85 & 40.92 & 43.84 & 44.05 & 43.99 & 44.32 & 44.45 & 44.38 \\
\hline
\end{tabular}

The LNG industry uses two measures of quality of natural gas, namely Higher Heating Value (HHV) and Wobbe index (WI), to ascertain the suitability of natural gas in different markets. They are both measures of energy content and while $H H V$ is equivalent to heat of combustion the $W I$ is an indicator of the interchangeability of fuel gases, as it gives a measure of the relative heat input into a burner at a fixed gas pressure. The relationship between the two is, 


$$
W I=\frac{H H V}{\sqrt{\rho / \rho_{\text {ref. }}}}
$$

where $\rho$ is the density of LNG mixture in the gaseous state and $\rho_{\text {ref. }}$, the reference density, is taken as the density of air at standard conditions. Both HHV and WI of LNG cargo were measured at the destination port and the values are reported in Table 1 using temperature and pressure of $0{ }^{\circ} \mathrm{C}$ and $0.1 \mathrm{MPa}$, respectively as the reference. Our model predicts both quantities to better than $0.3 \%$. In the present model HHV was obtained as mole average of heat of combustions and WI was obtained by means of Eq. (20). The values of heat of combustion for each relevant species where obtained from Ref [18].

Figures 3 and 4 illustrate the deviation of our results (integrated model) and those of Miana et al. [8] from the experimental data for two selected journeys. The results for other journeys [10] follow similar trends and the deviations do not exceed those shown in Figures 3 and 4.

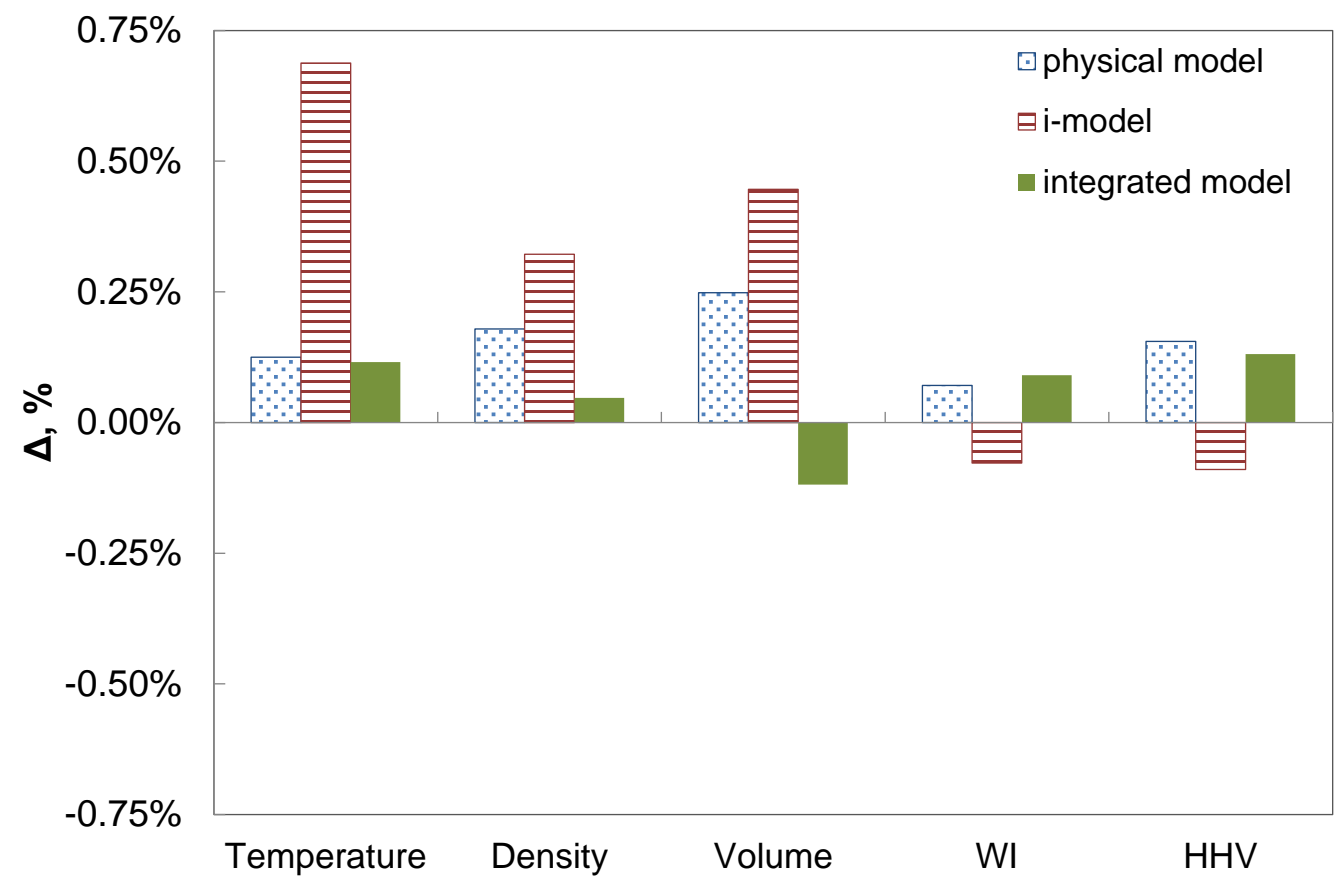

Figure 3 Relative Percentage Deviation, [ $\Delta=100\left(X_{\text {measured }}-X_{\text {model }}\right) / X_{\text {measured }}$ ], of the present model and Miana et al. [8] model from the measured data, for LNG Journey 2 


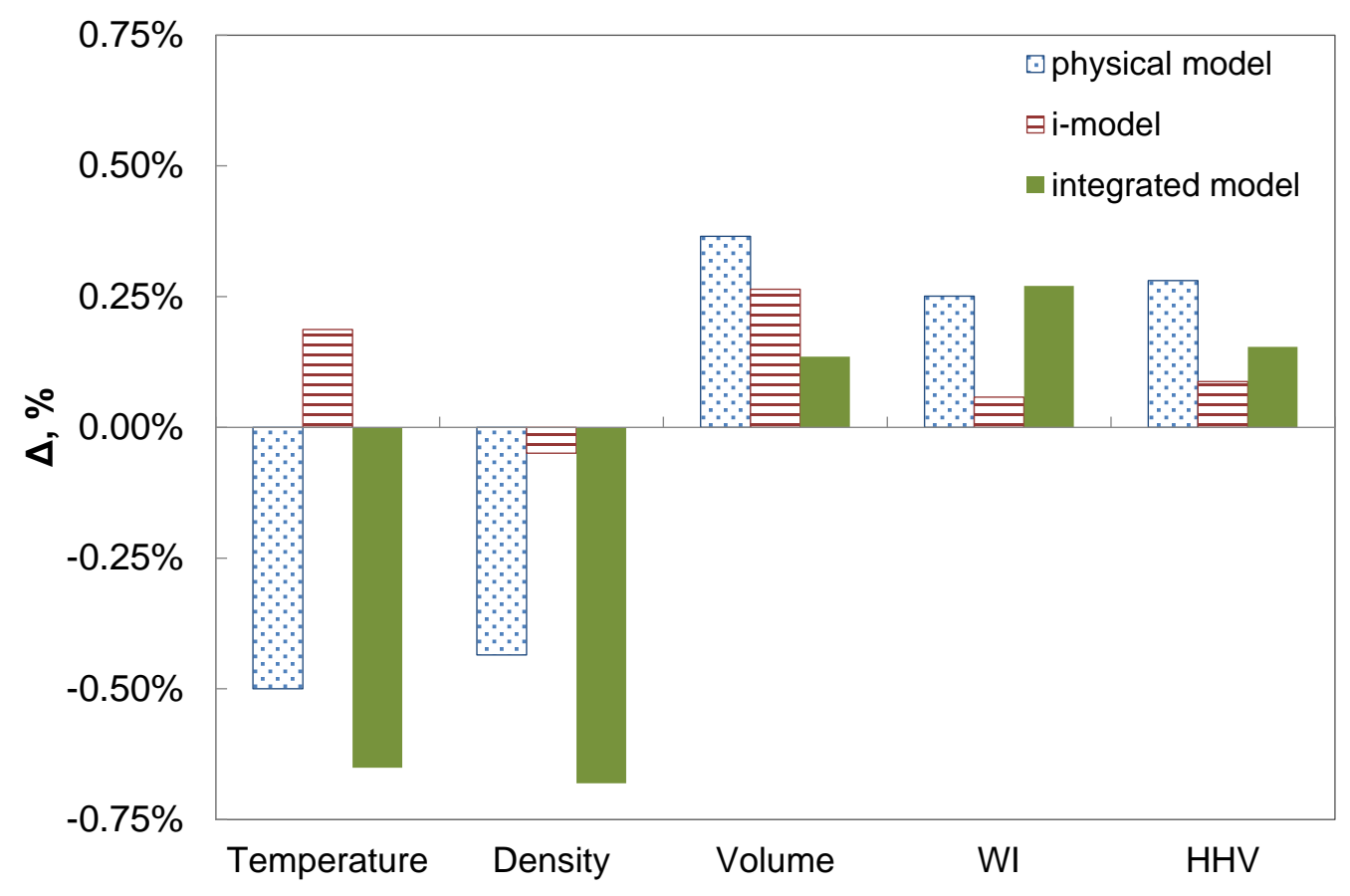

Figure 4 Relative Percentage Deviation, [ $\Delta=100\left(X_{\text {measured }}-X_{\text {model }}\right) / X_{\text {measured }}$ ], of the present model and Miana et al. [8] model from the measured data, for LNG Journey 3

As can be observed our model gives very similar deviations to Miana et al. [8] physical model and the differences between two models do not exceed $0.2 \%$ which is well within the uncertainty of both models. Neither model exhibit a bias, as there is neither systematic overestimation nor underestimation of measured variables. The improvement that the current model brings is that: (i) BOR is not fixed and can be predicted as part of the simulation; (ii) it can account for variable heat input during the weathering process and (iii) the LNG density is accurately calculated by means of experimentally based correlation.

\subsection{Sensitivity analysis}

A sensitivity analysis was performed using the described integrated model, wherein four cases were analysed on a long term basis. The cases analysed include sensitivities to: (i) composition, (ii) inventory, (iii) initial $\mathrm{N}_{2}$ content and (iv) outside temperature variations. We have opted to perform the weathering simulations for a standard 165,000 $\mathrm{m}^{3}$ containment tank used in industry. The storage tank characteristics are summarized in Table 2 and we have assumed the outside temperature to be $25{ }^{\circ} \mathrm{C}$, except for when we analysed the sensitivity to outside temperature variations. 
Table 2. LNG storage tank characteristics and sensitivity assumptions

\begin{tabular}{lr} 
Tank volume & $165,000 \mathrm{~m}^{3}$ \\
Tank height & $37.3 \mathrm{~m}$ \\
Internal diameter, $\boldsymbol{D}_{\mathrm{i}}$ & $76.4 \mathrm{~m}$ \\
External diameter, $\boldsymbol{D}_{\mathrm{o}}$ & $80.0 \mathrm{~m}$ \\
Tank operating pressure & $150 \mathrm{mbarg}$ \\
Wall section thermal conductivities, $\boldsymbol{k}:$ & \\
$\bullet \quad$ Resilient blanket [24] & $0.015 \mathrm{~W} / \mathrm{m} / \mathrm{K}$ \\
$\bullet \quad$ Expanded perlite [25] & $0.035 \mathrm{~W} / \mathrm{m} / \mathrm{K}$ \\
$\bullet \quad$ Concrete [19] & $1.6 \mathrm{~W} / \mathrm{m} / \mathrm{K}$ \\
Heat Ingress through the roof \& bottom slab & $100 \mathrm{~kW}$ \\
\hline LNG volume, $\boldsymbol{V}_{\text {tank }}$ & $160,000 \mathrm{~m}^{3}$
\end{tabular}

As already discussed the heat entering the tank was assumed to come through the roof, bottom slab and through the walls. Based on industry standard that BOR should not exceed $0.05 \%$ per day we estimated a total heat input in to the tank, assuming pure methane boil-off. Roughly $30 \%$ to $40 \%$ of the total heat entering into the tank comes through the lateral tank walls; the outstanding $60 \%$ to $70 \%$ comes from the roof and the bottom thermal slab. This is in good agreement with estimates based on operation of real storage tanks [10].

The weathering analysis was performed over a period of 52 weeks, which slightly exceeds the normal time that LNG is stored in LNG peak-shaving facilities. LNG peak-shaving facilities store LNG for longer periods of time, compared to regular regasification terminals. Hence, they are more subject to LNG weathering. In order to capture the variety of LNG available in the market we have performed the initial analysis using three commercial LNGs, that adequately describe a range of actual LNG compositions. Table 3 summarizes the composition of the LNGs used in this study. They include: (i) a 'light LNG' that primarily consists of methane with small amount of ethane present; (ii) a 'heavy LNG' where the amount of methane is around 91\% and (iii) 'LNG with $\mathrm{N}_{2}$ ', containing $0.26 \%$ of nitrogen. Both boiling temperature and the overall latent heat are given at the operating pressure of the tanks which in our simulation was 150 mbarg. 
Table 3. LNG compositions (mole fraction) used for the sensitivity case

\begin{tabular}{|c|c|c|c|}
\hline Component & Light LNG & Heavy LNG & LNG with $\mathrm{N}_{2}$ \\
\hline $\mathrm{C}_{1}$ & 0.9613 & 0.9164 & 0.9307 \\
\hline $\mathrm{C}_{2}$ & 0.0340 & 0.0576 & 0.0661 \\
\hline $\mathrm{C}_{3}$ & 0.0039 & 0.0204 & 0.0006 \\
\hline $\mathrm{i}-\mathrm{C}_{4}$ & 0.0004 & 0.0029 & 0.0000 \\
\hline $\mathrm{n}-\mathrm{C}_{4}$ & 0.0003 & 0.0022 & 0.0000 \\
\hline $\mathrm{i}-\mathrm{C}_{5}$ & 0.0000 & 0.0002 & 0.0000 \\
\hline$n-C_{5}$ & 0.0000 & 0.0000 & 0.0000 \\
\hline $\mathrm{N}_{2}$ & 0.0001 & 0.0003 & 0.0026 \\
\hline$T_{\text {boiling, }}{ }^{\circ} \mathrm{C}$ & -159.4 & -158.9 & -159.9 \\
\hline Overall Latent Heat, J/gmole [21] & 10,290 & 11,548 & 9,980 \\
\hline
\end{tabular}

\subsection{Sensitivity to initial LNG composition}

Figure 5 illustrates the BOG rate evolution as a function of the weathering period for three LNGs.

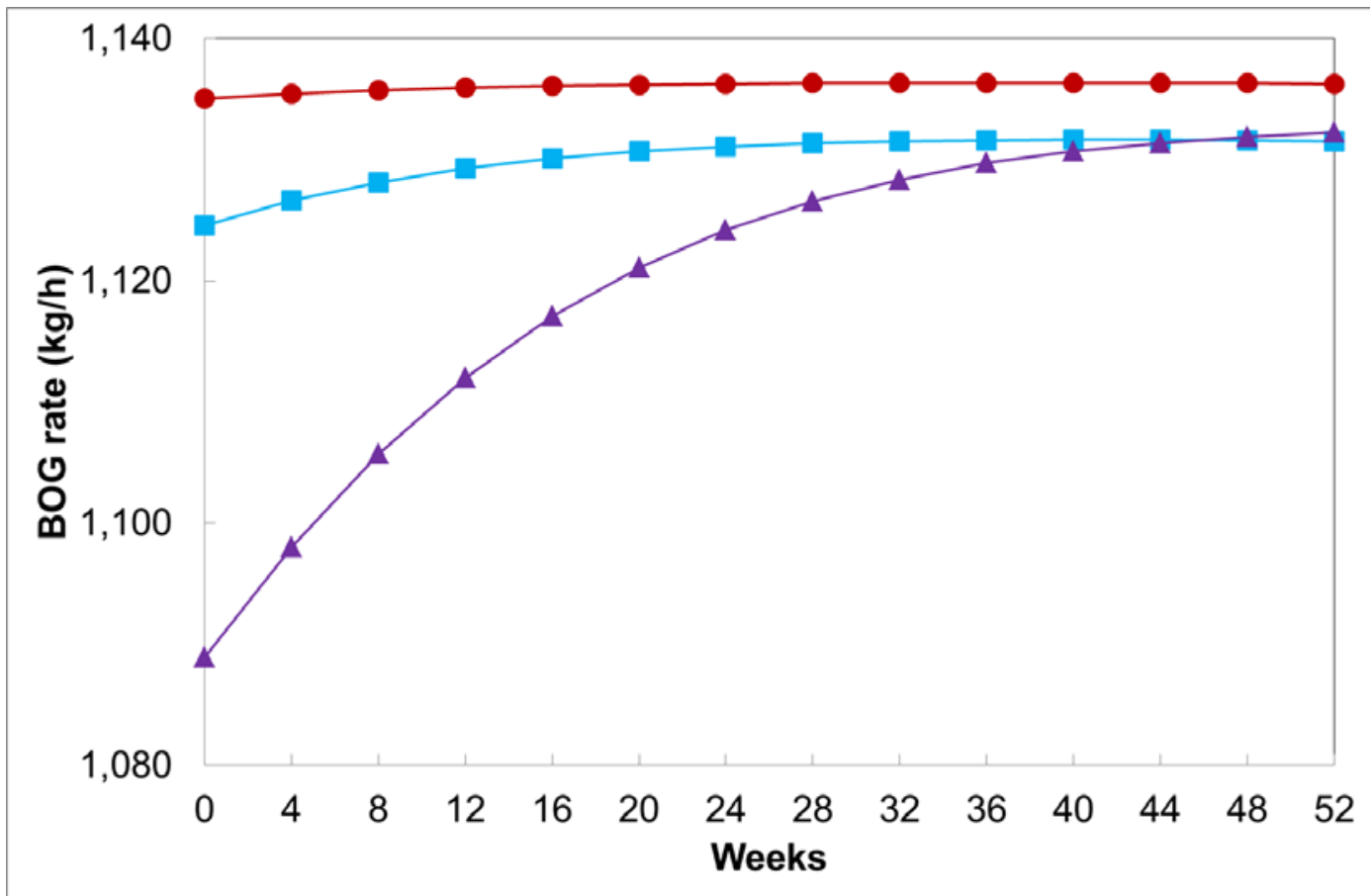

Figure 5. BOG evolution as a function of time for three different LNGs: ( — — Light LNG;

Heavy LNG; - $-\mathbf{A}$ - LNG with $\mathrm{N}_{2}$ ); To help distinguish between different lines, that refer to the values calculated by the proposed model, symbols have been added in this and all subsequent Figures. 
We observe that light LNG evaporates at constant BOG of the order of $1135 \mathrm{~kg} / \mathrm{h}$, which is only $0.5 \%$ smaller than the BOG of pure methane. This is not surprising as our simulations and previous work indicate [23] that for boiling LNG, that contains no nitrogen, the vapour consists primarily of methane $\left(\mathrm{y}_{\mathrm{CH} 4}>0.99\right)$. The heavy LNG also boils at approximately constant BOG, but at the rate 1 \% lower than that for light LNG. In this case the vapour also consists only of methane, but the boiling temperature and latent heat are slightly higher, see Table 2. As less heat enters the system and it takes more energy to evaporate the unit mass of LNG the evaporation rate is marginally lower. The most interesting case is that of LNG with $\mathrm{N}_{2}$. The BOG increases rapidly in the initial stages of weathering from the value of $1089 \mathrm{~kg} / \mathrm{h}$ to $1132 \mathrm{~kg} / \mathrm{h}$. This behaviour is entirely due to the presence of nitrogen that vaporizes preferentially to methane. Our simulations indicate that the initial vapour composition consists of only $94 \%$ methane and only when all of the nitrogen has evaporated does vapour revert to being essentially pure methane. As addition of nitrogen increases the latent heat of nitrogen-methane mixture, see Section 4.5, the amount of LNG vaporized will decrease. What is interesting is that even a very small amount of nitrogen present in LNG, in our case $0.26 \%$, can have a substantial influence on the initial BOG, leading to nearly $5 \%$ decrease. The decrease of BOG in the initial stages of weathering will result in BOR starting at a lower value, and gradually increasing to $0.04 \%$ that corresponds to nearly pure methane case. This strong sensitivity of BOG on nitrogen content will be further explored in Section 4.5.

The differences in BOG evolution have important consequences on the quality of LNG. Here we assess the quality of LNG during the weathering process by recourse to standard industry measures, namely High Heating Value (HHV) and Wobbe Index (WI). For illustrations purposes we have used the interim guidelines set for the US regulatory specifications in the White Paper on Natural Gas Interchangeability and Non-Combustion End Use [26], for the HHV and WI $\left(15.5^{\circ} \mathrm{C} / 15.5^{\circ} \mathrm{C}\right.$ and $\left.0.1 \mathrm{MPa}\right)$ for natural gas to be traded in US markets. The regulation sets targets values for maximum HHV and $W I$, but not for the minimum, which are defined by limiting the amount of butanes and inerts in the gas. In this regard, we have chosen the minimum (HHV and $W I$ ) based on the regulation [26], that the amount of non-methane species should not exceed $4 \%$ on the molar basis. Figures 6 and 7 illustrate the weathering effect on HHV and WI, of both LNG remaining in the tank and BOG generated. 


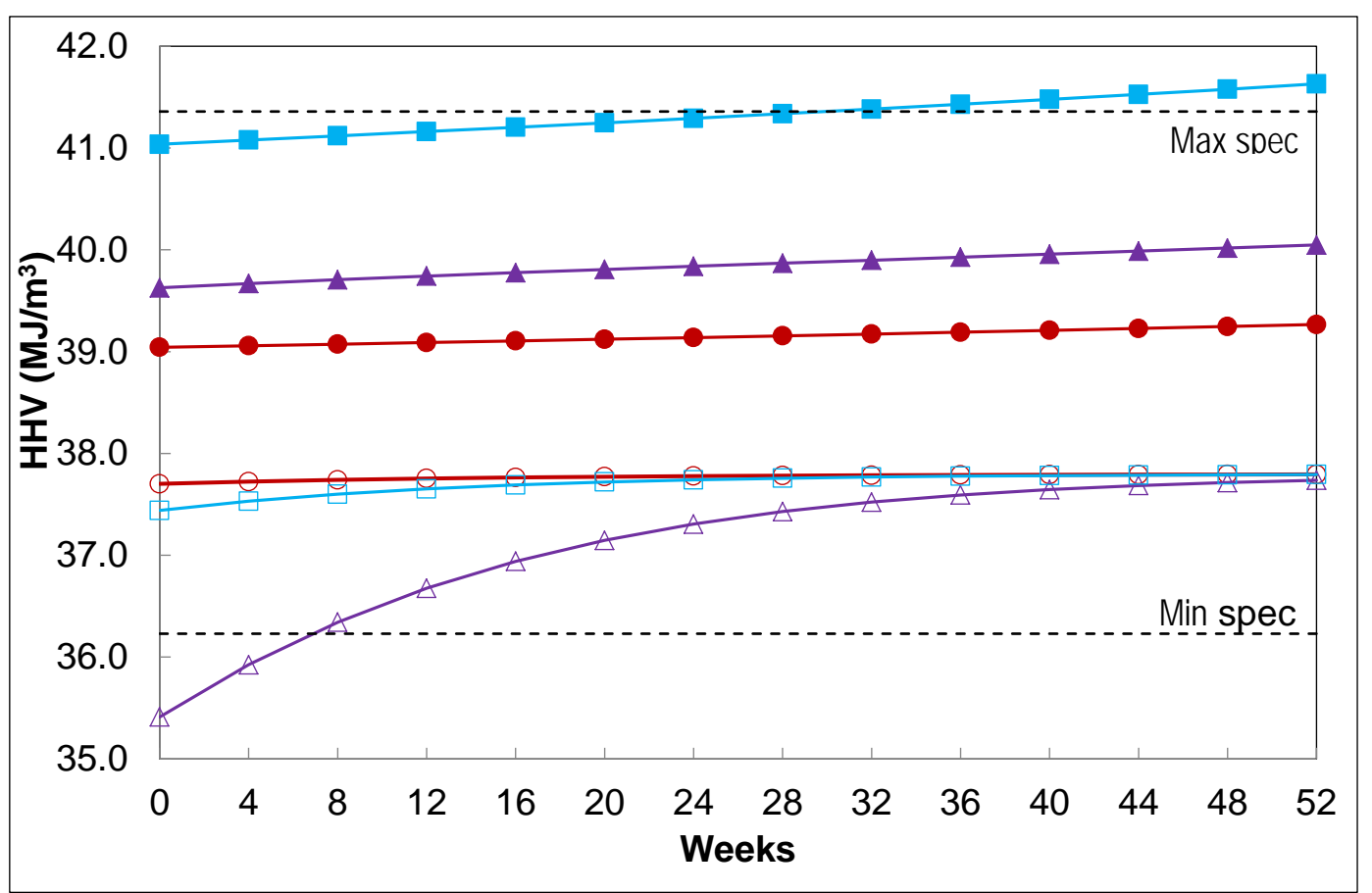

Figure 6 HHV evolution as a function of time for LNG and BOG for three different LNG mixtures used in this study. (-—- Light LNG; - - Heavy LNG; - - LNG with $\mathrm{N}_{2} ;-\bigcirc-$ BOG from Light LNG; $-\square-$ BOG from Heavy LNG; $-\triangle-$ BOG from LNG with $\mathrm{N}_{2}$ )

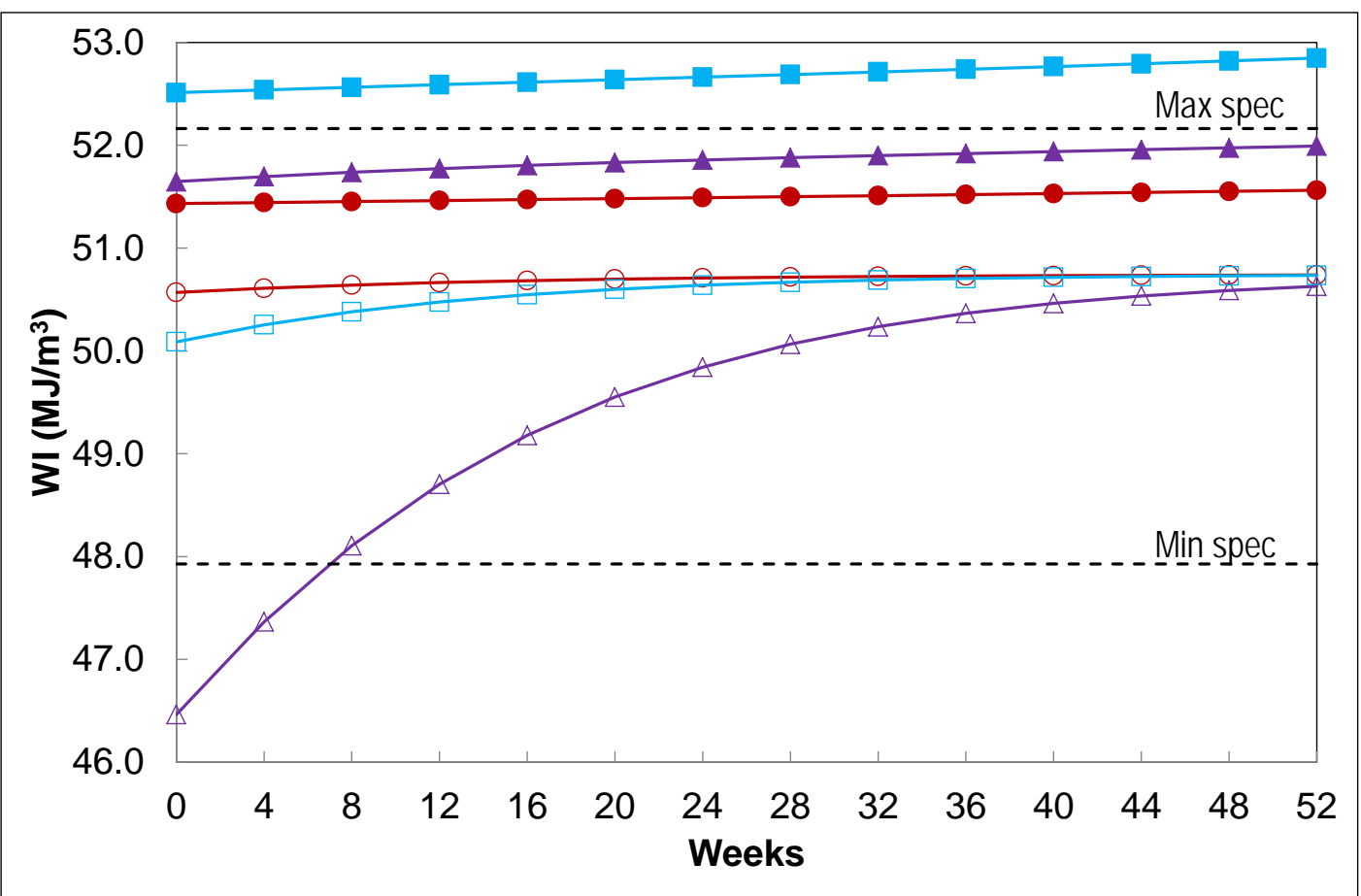

Figure $7 \mathrm{WI}$ evolution as a function of time for LNG and BOG for three different LNG mixtures used in this study. (- - Light LNG; - - Heavy LNG; - - LNG with $\mathrm{N}_{2} ;-\mathrm{O}-\mathrm{BOG}$ from Light LNG; $-\square-$ BOG from Heavy LNG; $-\triangle-$ BOG from LNG with $\mathrm{N}_{2}$ ) 
We observe that although for all three LNGs the HHV and WI increase with time, the Light LNG and LNG with $\mathrm{N}_{2}$ remain within the US market quality specifications during the whole 52 weeks of simulations. The Heavy LNG behaviour is interesting as the two measures (WI and HHV give slightly different results. If we use the WI measure the Heavy LNG is outside the US spec and could not be traded in the US markets, while the HHV measure indicates that initially it starts just within the spec but after 34 weeks gets sufficiently weathered to become out of spec. In the assessment of the BOG generated, the key parameter is the initial content of nitrogen. If it is sufficiently high the BOG will contain a large amount of nitrogen making the natural gas out of spec in the initial stages of weathering. As the nitrogen content of the BOG decreases with time, the natural gas will become marketable based on US HHV and WI specifications. Furthermore, we observe that both $H H V$ and $W I$ of $B O G$ tend to the value for pure methane $\left(H H V_{\text {methane }}=37.69\right.$ $\mathrm{MJ} / \mathrm{m}^{3}$ and $W I_{\text {methane }}=50.87 \mathrm{MJ} / \mathrm{m}^{3}$ ) as the amount of nitrogen in BOG progressively decreases.

\subsection{Sensitivity to initial LNG inventory}

A sensitivity analysis was carried out to investigate the effect of variation in the initial LNG inventory on the generated BOG. The LNG inventory was varied between 15,000 and 160,000 $\mathrm{m}^{3}$, in a storage tank of capacity of $165,000 \mathrm{~m}^{3}$ and the simulations were performed for both the light LNG and heavy LNG mixtures, compositionally described in Table 1. Figure 8 illustrates the vaporization rate, expressed as BOG, as a function of the amount of LNG evaporated. The amount of LNG evaporated was measured in terms of number of moles evaporated divided by the initial number of moles of LNG, expressed as a percentage. Expressing the results in terms of percentage of LNG evaporated using volumetric or mass basis has only the effect of resizing the $x$ axis, but no impact on any of the features observed. For clarity only results for the smallest inventory $\left(15,000 \mathrm{~m}^{3}\right)$ and highest inventory $\left(160,000 \mathrm{~m}^{3}\right)$ are presented, for both LNG mixtures. 


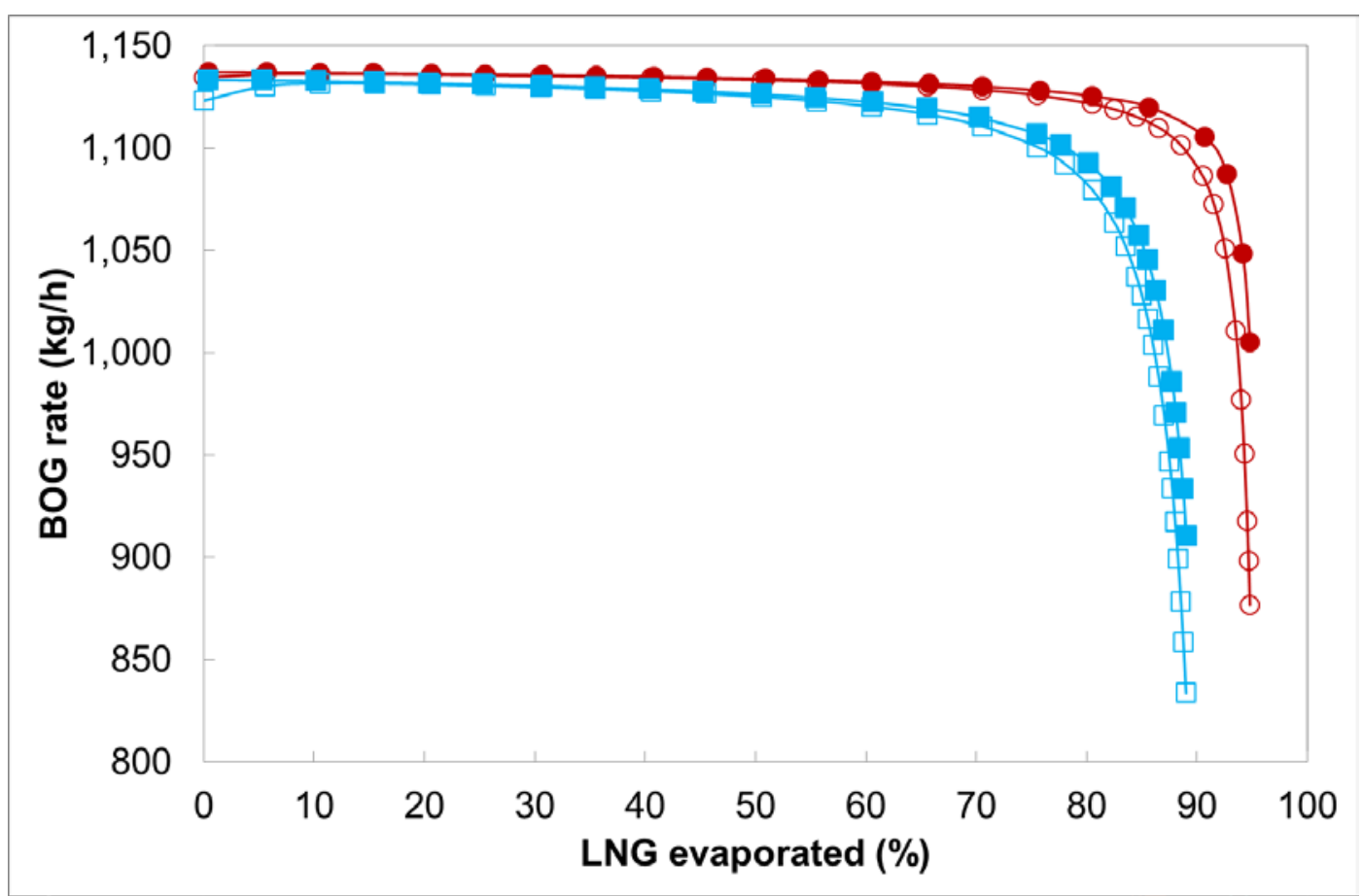

Figure 8 BOG as a function of the amount of LNG evaporated for different scenarios (-— Light LNG, storage tank initially filled with $15,000 \mathrm{~m}^{3}$; — - — Light LNG, storage tank initially filled with $160,000 \mathrm{~m}^{3}$; - — - Heavy LNG, storage tank initially filled with $15,000 \mathrm{~m}^{3} ;-\square-$ Heavy LNG storage tank initially filled with $160,000 \mathrm{~m}^{3}$ )

We observe that in the initial stages of weathering the BOG rate is constant of the order of 1140 $\mathrm{kg} / \mathrm{h}$, and is independent of the amount of LNG present. This is not surprising as in the initially the vapour consist exclusively of methane, hence neither the differential latent heat nor the boiling temperature change appreciable. As a result the BOR is also essentially constant of the order of $0.04 \%$ for tank initially filled with $160,000 \mathrm{~m}^{3}$ LNG and $0.44 \%$ for with tank initially filled with $15,000 \mathrm{~m}^{3}$.

As the LNG evaporates the remaining liquid gets richer in heavier hydrocarbons. This has, as discussed previously [23], two thermodynamic consequences. The boiling temperature and the differential latent heat increase. The resulting reduction in the heat ingress and the need to provide more energy to vaporize the same amount of LNG, now richer in heavy components, results in drastic decrease of BOG, as observed in Figure 8. As expected the Heavy LNG gets richer in heavy components quicker than the Light LNG and BOG starts decreasing earlier, at approximately $60 \%$ compared with $85 \%$ for Light LNG. It can be also observed, in Figure 8 , that the tank filled up to $160,000 \mathrm{~m}^{3}$ capacity exhibits a slightly earlier decrease in BOG than the tank with the smaller initial amount of LNG. This is a direct consequence of the indirect differential latent heat. As the LNG gets richer in heavier hydrocarbons, its boiling temperature increases and hence 
some of the ingress heat will go towards heating up the remaining LNG. For a given amount of LNG evaporated the storage tank with initially more LNG will have more liquid remaining. Hence more heat will be required to increase its temperature to a new boiling point, thus reducing the amount of heat available for evaporating the LNG. The overall result will be an earlier decrease in BOG for an initially more filled storage tank.

Due to range of validity of Klosek-McKinley equation for liquid density we have stopped the simulations before a complete evaporation of the tank. This late stage is usually of marginal interest to weathering process and the thermodynamic behaviour has been already extensively analysed [23].

\subsection{Sensitivity to initial $N_{2}$ content}

We have already observed, see Figure 5, that the presence of nitrogen in LNG decreases the BOG markedly during the initial stages of weathering. Here we examine this effect further by analysing the sensitivity of BOG to the amount of $\mathrm{N}_{2}$ present in originally stored LNG. The analysis is performed by comparing an actual Light LNG composition to three hypothetical $\mathrm{N}_{2}$ enriched LNG mixtures of up to $1.5 \% \mathrm{~N}_{2}$ content. Table 4 summarizes the composition of the four mixtures. In order to make the comparison on the equal footing we have maintained the ratios of the hydrocarbon species constant for all four mixtures.

Table 4. Nitrogen enriched LNG mixtures used for the sensitivity to initial $\mathrm{N}_{2}$ content

\begin{tabular}{|c|c|c|c|c|}
\hline Component (mole fraction) & Light LNG & $0.5 \% \mathrm{~N}_{2}$ & $1.0 \% \mathrm{~N}_{2}$ & $1.5 \% \mathrm{~N}_{2}$ \\
\hline $\mathrm{C}_{1}$ & 0.9613 & 0.9566 & 0.9517 & 0.9470 \\
\hline $\mathrm{C}_{2}$ & 0.0340 & 0.0338 & 0.0337 & 0.0335 \\
\hline $\mathrm{C}_{3}$ & 0.0039 & 0.0039 & 0.0039 & 0.0038 \\
\hline $\mathrm{iC}_{4}$ & 0.0004 & 0.0004 & 0.0004 & 0.0004 \\
\hline $\mathrm{nC}_{4}$ & 0.0003 & 0.0003 & 0.0003 & 0.0003 \\
\hline $\mathrm{N}_{2}$ & 0.0001 & 0.0050 & 0.0100 & 0.0150 \\
\hline$T_{\text {boiling }},{ }^{\circ} \mathrm{C}$ & -159.4 & -160.9 & -162.4 & -163.8 \\
\hline Overall Latent Heat, J/mole [21] & 10,290 & 10,351 & 10,410 & 10,461 \\
\hline
\end{tabular}


Figure 9 illustrates the evolution of the BOG rate for four different $\mathrm{N}_{2}$ enriched LNG mixtures listed in Table 3. We observed a marked decrease in the BOG in the initial stages of weathering of up to $13 \%$.

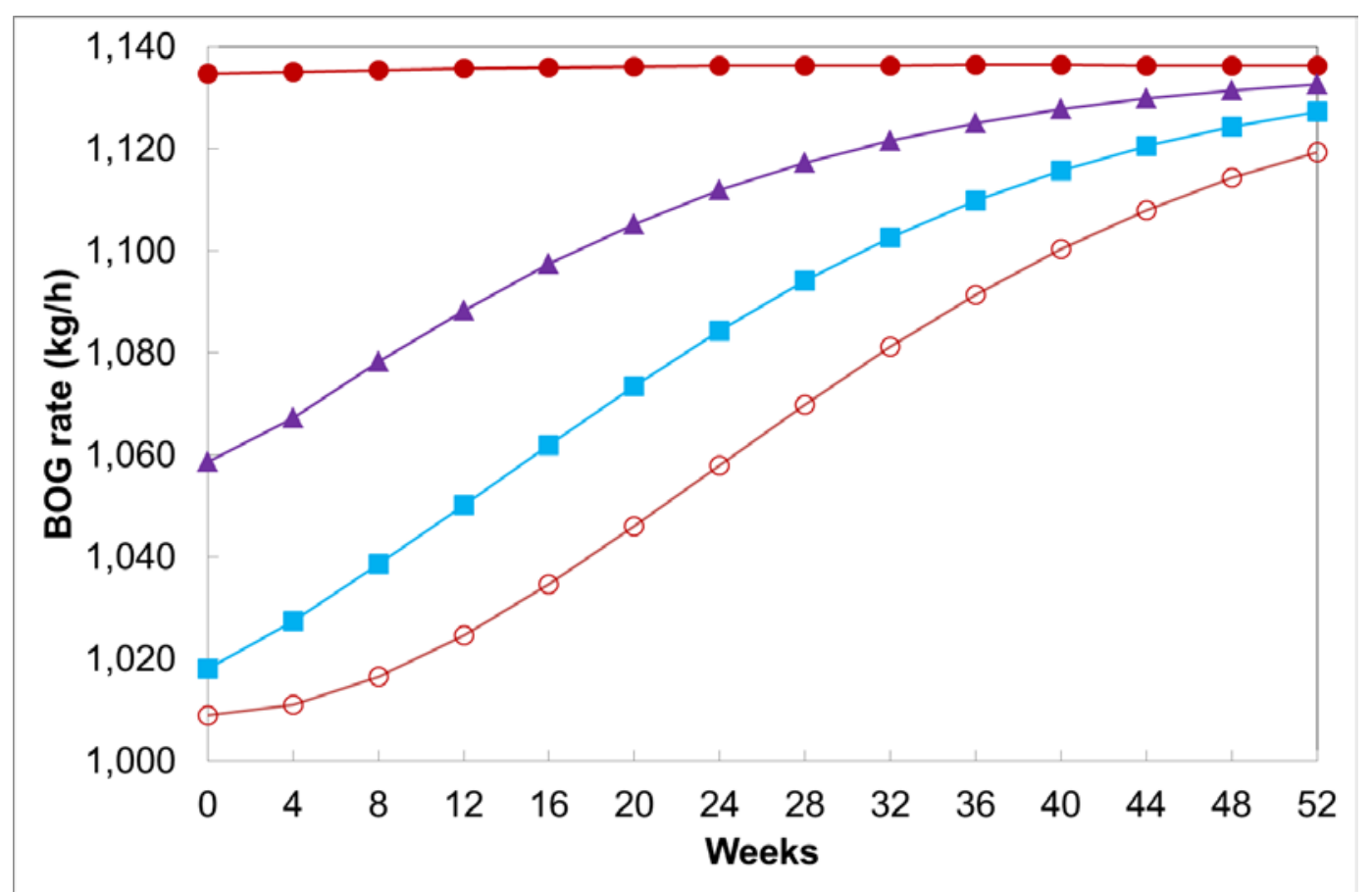

Figure 9 BOG evolution as a function of time for four different LNGs: (—— Light LNG; — - L LNG with $0.5 \% \mathrm{~N}_{2} ;$ - — LNG with $1.0 \% \mathrm{~N}_{2} ;$ - $\mathrm{O}$ - LNG with $1.5 \% \mathrm{~N}_{2}$ )

In order to understand the mechanism behind the decrease, we examine the thermodynamics of the mixture. The increase of the amount of $\mathrm{N}_{2}$ in the LNG mixtures leads to two thermodynamic effects, namely lowering the boiling point of the mixture and increasing the latent heat needed to vaporize an LNG drop as summarized in Table 4. As LNG starts to weather, $\mathrm{N}_{2}$, being the most volatile component in the mixture, will preferentially vaporize. Figure 10 illustrates the change in $\mathrm{N}_{2}$ composition of the vapour and liquid phases as a function of time. We observe a rapid decrease in the nitrogen concentration. As a consequence the boiling temperature of the remaining LNG will increase. The simulations indicate that, within the 52 weeks period examined, the boiling temperature of all mixtures will reach $114 \mathrm{~K}$. Such a small change in the boiling temperature during the weathering process, will result in a rather small indirect differential latent heat component. The simulations indicate that the indirect differential latent heat is less than $0.1 \%$ of the total differential latent heat. 

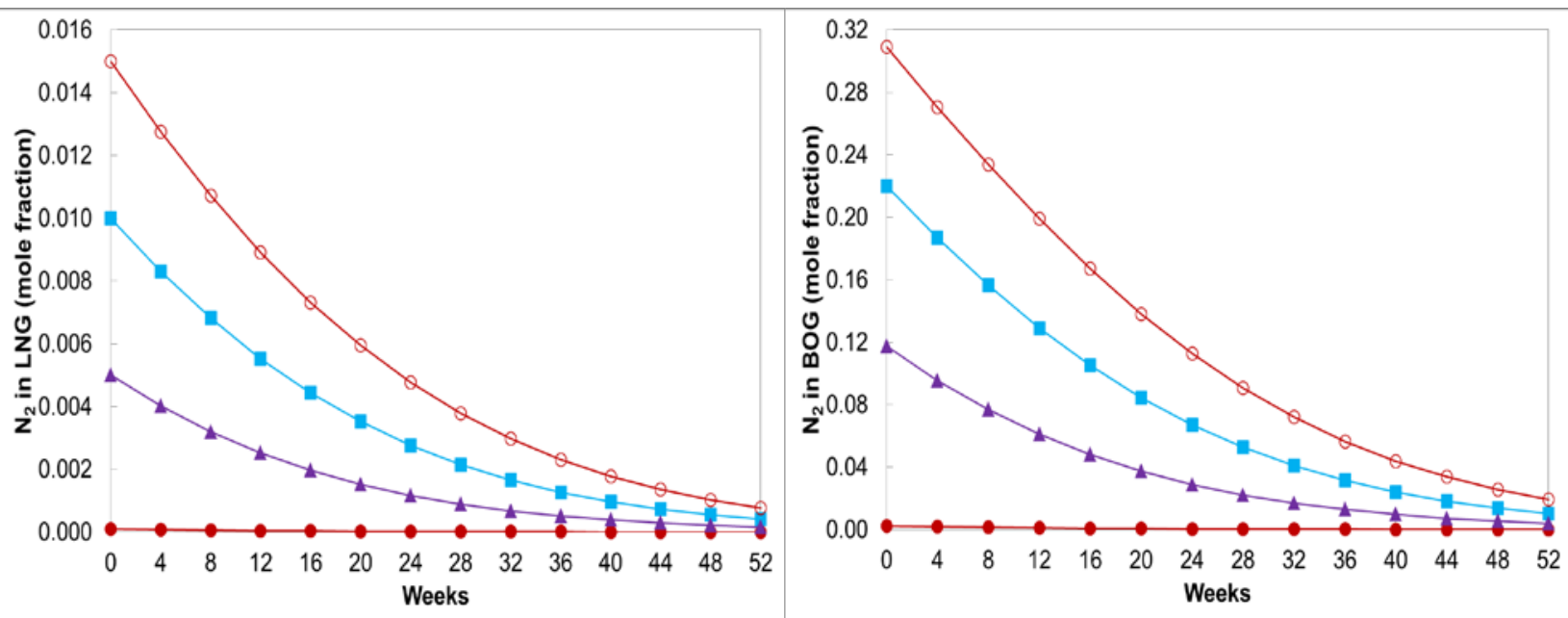

Figure 10 The change of composition of $\mathrm{N}_{2}$ due to weathering: ( - - Light LNG; $-\mathbf{\Delta}-$ LNG with $0.5 \% \mathrm{~N}_{2} ;-$ - LNG with $1.0 \% \mathrm{~N}_{2} ;-\mathrm{O}$ - LNG with $1.5 \% \mathrm{~N}_{2}$ )

Although the decrease in the boiling temperature has minimal effect on the differential latent heat, it will lead to a larger temperature differential between the LNG and the surroundings, at least in the initial stages of the process. As a consequence, the heat flux into the tank will increase. However, the effect is again only minor and the heat flux will increase by at most $1.0 \%$. Therefore the determining factor in the reduction of $\mathrm{BOG}$ for $\mathrm{N}_{2}$ rich mixtures is due to the increase in the direct latent heat required to vaporize a drop of LNG. Judging by entries in Table 4 the difference in the latent heat between four mixtures is relatively small. However, this is the overall latent heat required to completely evaporate the mixture. As the mixture experiences preferential evaporation of lighter component the initial LNG vaporized will consists of large amount of nitrogen as illustrated in Figure 10a. Hence, one needs to consider the differential molar latent heat required to vaporize a drop of LNG at each stage of the process. At the initial stage of vaporization of LNG containing $1.5 \% \mathrm{~N}_{2}$, see Figure 10, the vapour phase will consists of $31 \%$ nitrogen. The latent heat needed to evaporate a mixture consisting of $31 \%$ nitrogen and $69 \%$ methane will be approximately $40 \%$ higher than the latent heat of pure methane. This roughly translates into a decrease of molar based BOG (measured in moles/h) by a similar amount. However, if we examine, as we traditionally do, the mass based BOG, expressed in $\mathrm{kg} / \mathrm{h}$, then the decrease is smaller and no longer proportional to the direct latent heat. This is the consequence of the increase in the molecular weight of the generated vapour which is initially higher than in the base case, due to a large amount of $N_{2}$ present in the vapour. As illustrated in Figure 10, the nitrogen content of the vapour can reach up to $30 \%$. The increase in molecular weight of vapour compared to the base case (Light LNG) explains a different initial slope of BOG for 1.5\% $\mathrm{N}_{2}$ rich LNG in Figure 9. As the preferentially evaporation of nitrogen continues, the amount of nitrogen decreases in time, as illustrated in Figure 10. The direct differential molar latent heat will consequently decrease, resulting in increase in BOG in later stages of weathering, as illustrated in Figure 9. 
What is interesting to observe is that further increase in the initial nitrogen content does not lead to further decrease of BOG. Figure 11 illustrates the variation of the initial BOG rate with the initial amount of $\mathrm{N}_{2}$ in the LNG. We observe a minimum at around $1.5 \%$ of $\mathrm{N}_{2}$. The minimum is a direct consequence of the increase in the molecular weight of the generated vapour which is rich in nitrogen. As we increase the amount of nitrogen in the initial LNG, the boiling temperature will decrease and the direct differential molar latent heat will increase. For instance, for a LNG mixture that contains $4 \%$ by mole of nitrogen, the boiling temperature will drop by approximately $6{ }^{\circ} \mathrm{C}$ and direct differential molar latent heat will increase by approximately $8 \%$, compared to LNG mixture that contains $1.5 \%$ by mole of nitrogen. The effect of temperature is small resulting in $1 \%$ increase in BOG, while the effect of the latent heat will dominate and will led to the overall decrease of BOG of approximately $7 \%$. However, in the initial stages of boiling the BOG vapour being released by $4 \% \mathrm{~N}_{2}$ LNG mixture will consist of approximately $60 \%$ nitrogen, compared to $30 \%$ for $1.5 \% \mathrm{~N}_{2}$ LNG mixture. The increase in the molecular weight of the resulting vapour will result in lower total differential latent heat per unit mass. Hence, the standard BOG expressed in mass terms, rather than in terms of number of moles, will be higher for the LNG mixture that contains $4 \%$ by mole of nitrogen. This offers an intriguing possibility of using nitrogen to minimize the BOG, during storage stage, as long as the generated BOG vapour is not transmitted to the outside gas network.

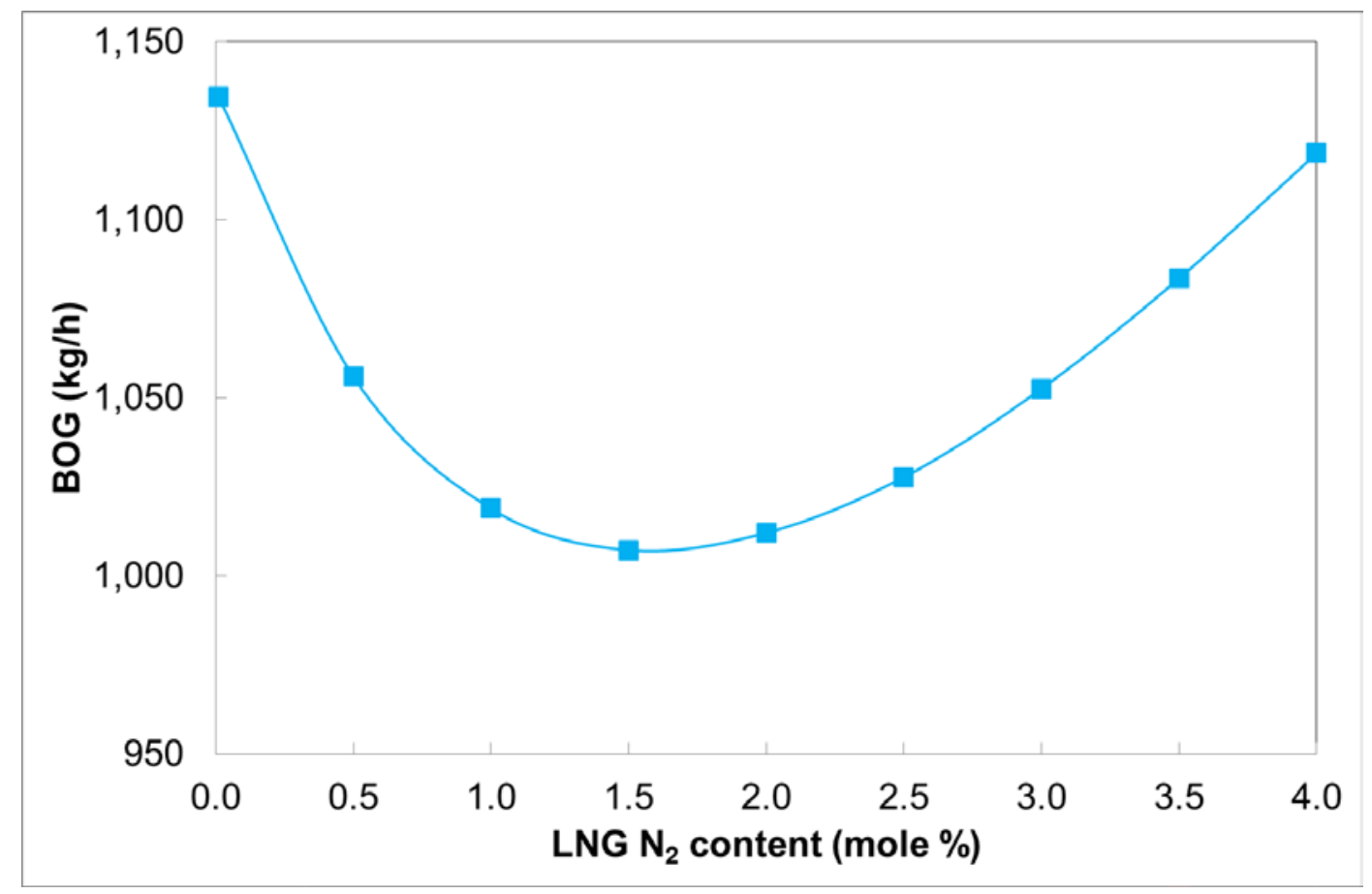

Figure 11 Initial BOG evolution as a function of the initial $\mathrm{N}_{2}$ content of LNG 
A sensitivity case is presented to analyse the effect of outside temperature variations on BOG generation from stored LNG. The analysis is based on the initial filling of $160,000 \mathrm{~m}^{3}$ of LNG and the outside temperature is varied by $10^{\circ} \mathrm{C}$ from $5-35^{\circ} \mathrm{C}$. The LNG mixture containing $1.5 \%$ of $\mathrm{N}_{2}$ on molar basis, compositionally defined in Table 4 , has been used, as it showed greatest variation of BOG, see Figure 9, over the period of interest.

Figure 12 illustrates the sensitivity of BOG vaporization rate to the outside temperature variation. On average the BOG rate increases by approximately $2 \%$ for every $10^{\circ} \mathrm{C}$ increase in the outside temperature. The change in BOG is very weakly dependent on composition and is not a function of weathering, at least not during the storage time of interest to LNG industry. It is primarily driven by the temperature differential between the tank and the surroundings, taking into account that the heat coming through the slab and roof section of the tank is very weakly dependent on the temperature of surrounding air. Hence, for LNG tanks currently operated by industry one can safely assume rule-of-thumb that $1^{\circ} \mathrm{C}$ change in the outside temperature will change the BOG by approximately $0.2 \%$.

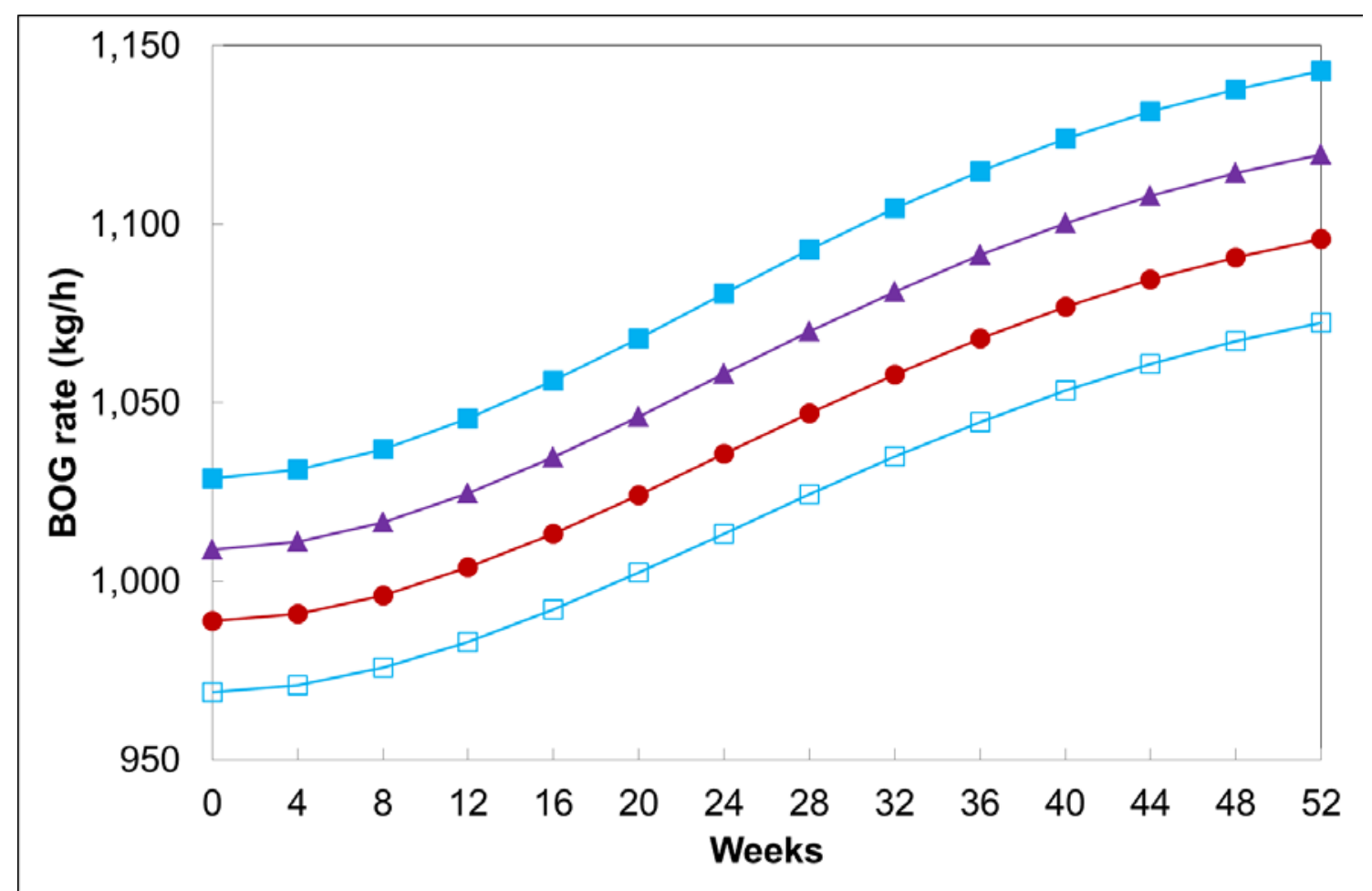

Figure 12 The change in BOG due to change in outside air temperature: $\left(-\square-\mathrm{T}_{\text {air }}=5^{\circ} \mathrm{C}\right.$;

$$
\text { - } \mathrm{T}_{\text {air }}=15^{\circ} \mathrm{C} ;-\Delta-\mathrm{T}_{\text {air }}=25^{\circ} \mathrm{C} ;-1-\mathrm{T}_{\text {air }}=35^{\circ} \mathrm{C} \text { ) }
$$




\section{CONCLUSIONS}

A stand-alone model for rigorous prediction of LNG weathering in containment storage tanks, typically used in regasification terminals, has been developed. It fills an important gap in the LNG regasification industry, as accurate prediction of LNG weathering can make a significant contribution to optimizing normal operations, as well as to capturing upside opportunities in long term LNG storage. The model builds on previously developed weathering models and provides a number of advances in so far as: (i) heat ingress is calculated based on the outside temperature and LNG composition, that allows for daily or seasonal variation; (ii) Boil-off-Ratio is not an input parameter, but is calculated as part of the simulations and (iii) the LNG density is estimated using an accurate experimentally based correlation. The model has been coded using MS Visual Basic 6.0 .

The model was tested using measured data and in particular it was used to predict the LNG properties following marine transport ranging from 98 to $390 \mathrm{~h}$ at sea. The agreement with measured data that consisted of the composition, volume reduction, density and boiling temperature of transported LNG was deemed more than satisfactory and within the current industry requirements.

It was observed that the initial amount of nitrogen in LNG will have a marked effect on BOG in the initial stages of weathering. The presence of nitrogen leads to marked decrease of BOG that can be explained by preferential evaporation of nitrogen and resulting increase in the direct differential latent heat. As the initial BOG generated is very rich in nitrogen the resulting 'natural gas' falls out of spec by any regulatory measures.

Although BOG expressed in molar terms will continue to decrease with increasing amount of nitrogen, the standard BOG expressed in mass terms, will exhibit a minimum at around $1.5 \%$ nitrogen. The analysis carried out, in terms of influence of nitrogen on the latent heat and the boiling temperature of the LNG mixture, concluded that the observed minimum is a direct consequence of the increase in the molecular weight of the generated BOG vapour, which is rich in nitrogen. The existence of a minimum in BOG offers an intriguing possibility of operating LNG storage tanks by using nitrogen to minimize the BOG generation during the storage stage. Providing the generated BOG vapour is not transmitted to the outside gas network and is instead recirculated back to the storage unit. 
For current LNG tanks, used in storage and regasification facilities, one can, based on the analysis carried out in this work, devise a simple rule of thumb that $1{ }^{\circ} \mathrm{C}$ change in the ambient temperature will lead to a change in BOG of $0.2 \%$. 


\section{REFERENCES}

[1] World Energy Outlook - Are we entering a golden age of gas? Special Report. International Energy Agency. France; 2011.

[2] Colson D, Haquin N, Malochet M. Reduction of boil-off generation in cargo tanks of liquid natural gas carriers - Recent developments of Gaztransport \& Technigaz (GTT) cargo containment systems. 25 $5^{\text {th }}$ World Gas Conference, Kuala Lumpur; 2012.

[3] Yang Y, Kim J, Seo H, Lee K, Yoon I. Development of the world's largest above-ground full containment LNG storage tank. Korea Gas Corporation. $23^{\text {rd }}$ World Gas Conference, Amsterdam; 2006.

[4] Churchill, SW. Chem. Eng. Progress Symp. Series. 1962; 58(11): 55.

[5] Neill DT, Hashemi HT, Sliepcevich CM. Boil-off rates and wall temperatures in above ground LNG storage tanks. Chem. Eng. Progress Symp. Series. 1968; 64:111-9.

[6] Kountz KJ. Weathering of LNG in on-board storage tanks. Institute of Gas Technology, IGT project report 32034-02; 1999.

[7] Dimopoulos GG, Frangopoulos CA. A Dynamic model for liquefied natural gas evaporation during marine transportation. Int. J. of Thermo. 2008; 11(3): 123-31.

[8] Miana M, Del Hoyo R, Rodrigálvarez V, Valdés JR, Llorens R. Calculation models for prediction of liquefied natural gas (LNG) ageing during ship transportation. App. Energy; 2010; 87(5):1687-700.

[9] Chen QS, Wegrzyn J, Prasad V. Analysis of temperature and pressure changes in liquefied natural gas (LNG) cryogenic tanks. Cryogenics; 2004; 44:701-9.

[10] Adom E, Islam SZ, Ji, X. Modelling of boil-off gas in LNG tanks: A case study. Int. J. Eng. Tech.; 2010; 2(4):292-6.

[11] Pellegrini LA, Moioli S, Brignoli F, Bellini C. LNG Technology: The weathering in aboveground storage tanks. Ind. Eng. Chem. Res. 2014; 53(10):3931-7.

[12] Shah JM, Aarts JJ. Effect of weathering of LNG in storage tanks. Adv. Cryogenics Eng. 1974; 19: 253-60.

[13] Aspelund A, Gjovag G A, Neksa P, Kolsaker K. LNG-Chain, a calculation tool for natural gas quality in small scale LNG distribution chains. Proc. $21^{\text {th }}$ Int. Cryog. Eng. Conf. (ICEC21). Prague: Icaris; 2007; CR06-133.

[14] Danesh A. PVT and phase behaviour of petroleum reservoir fluids. The Netherlands: Elsevier Science; 1998.

[15] Poling B, Prausnitz J, O'Connell J. The properties of gases and liquids. $5^{\text {th }}$ ed. New York: McGraw-Hill; 2007. 
[16] LNG Custody Transfer Handbook. Groupe International des Importateurs de Gaz Naturel Liquéfié (GIIGNL), $3^{\text {rd }}$ ed. Paris: GIIGNL; 2010.

[17] Albrigh LF. Albright's Chemical Engineering Handbook. Boca Raton: CRC Press, Taylor \& Francis Group; 2009.

[18] Lemmon EW, Huber ML, McLinden MO. NIST Standard Reference Database 23: Reference Fluid Thermodynamic and Transport Properties-REFPROP, Version 9.1, Standard Reference Data Program. Gaithersburg, MD: National Institute of Standards and Technology; 2013.

[19] Perry H, Green D. Perry's Chemical Engineers' Handbook. 50 $0^{\text {th }}$ ed. New York: McGraw-Hill; 1985.

[20] MS Visual Basic software. Microsoft corp. Version 6.0. USA; 1998.

[21] Aspen Hysys process simulator. Aspen Technology, Inc., V7.2 (24.0.0.7263). USA; 2010.

[22] Bett KE, Rowlinson JS, Saville G. Thermodynamics for chemical engineers. London: MIT Press; 1975.

[23] Conrado C, Vesovic V. The influence of chemical composition on vaporization of LNG and LPG on unconfined water surfaces. Chem. Eng. Sci. 2000; 55:4549-62.

[24] Resilient blanket vendor data sheet. Isover, Saint-Gobain Group. France; 2006.

[25] Expanded perlite vendor data sheet. CECA, Arkema Group. France; 2006.

[26] White paper on natural gas interchangeability and non-combustion end use. Natural Gas Council Plus. Interchangeability Work Group. USA; 2005. 


\section{Nomenclature}

BOG Boil-off Gas

BOR Boil-off Rate

EOS Equation of State

GIIGNL International Group of Liquefied Natural Gas Importers

HHV Higher Heating Value

IGT Institute of Gas Technology

LNG Liquefied Natural Gas

PR-EOS Peng Robinson Equation of State

SRK Soave Redlich Kwong

VLE Vapor-Liquid Equilibrium

WI Wobbe index 